\title{
Comparison of Stress Distribution and Deformation of Four Prosthetic Materials in Full-mouth Rehabilitation with Implants: A Three-dimensional Finite Element Study
}

Yemineni Bhavan Chand ${ }^{1}$, Jaideep Mahendra ${ }^{2}$, Nasina Jigeesh ${ }^{3}$, Little Mahendra ${ }^{4}$, Lakshmi Shivasubramanian ${ }^{5}$, Shareen Babu Perika ${ }^{6}$

\begin{abstract}
Aim: This study aimed to compare the von Mises stress distribution and deformation on the implant, abutment, and abutment screw using metal-ceramic, zirconia, polyether ether ketone (PEEK), and Trinia as prosthetic materials for full-mouth cement-retained implant prosthesis using finite element analysis.

Materials and methods: Four, 3-dimensional mandibular models were designed using Solidworks software. Six conical implants of $4.5 \times 11.5 \mathrm{~mm}$, with an internal hexagonal abutment, were fabricated and placed. The physical properties of the implant components, bone, and crowns were simulated to mesh the three-dimensional finite element models. The bite was recorded, and various contact points were marked, on which 50 $\mathrm{N}$ loads were applied. The von Mises stress distribution and resultant deformation were analyzed using the finite element method.

Results: Higher stress distribution was recorded on the implants, abutments, and abutment screws when zirconia and PEEK prosthesis were used in comparison to metal-ceramic and Trinia. In consideration of deformation, zirconia and Trinia resulted in higher deformation of the implant assembly, abutment, and abutment screw when compared to metal-ceramic and PEEK prosthesis. Anterior implants showed a higher deformation and stress distribution when compared to posterior implants for all four prosthetic materials.

Conclusion: Within the limitations of the study, metal-ceramic and Trinia showed less stress distribution, while metal-ceramic and PEEK exhibited less deformation on implant and its components. Hence in future, Trinia and PEEK along with metal-ceramic can be promising prosthetic materials of choice in full-mouth rehabilitation with implants.

Clinical significance: Considering the deformation and stress distribution on the implant and its components, the selection of prosthetic material in full-mouth rehabilitation has always been a challenge. Findings of the abovementioned cross-sectional observational study could give an overall insight into materials such as metal-ceramic and Trinia as materials of choice, which can provide a basis for future clinical trials. Keywords: Deformation, Finite element analysis, Implant prosthesis, PEEK, Trinia.

The Journal of Contemporary Dental Practice (2020): 10.5005/jp-journals-10024-2959
\end{abstract}

\section{INTRODUCTION}

In the modern era, dental implants provide edentulous patients with an enhanced functional and confident life. Fixed dental and implant prosthesis has been accepted as an integral part of prosthetic dentistry for edentulous patients ever since the late 1950s. The success rate of implants is usually high, which may be due to the inherent contributed factors such as effectiveness, convenience, and affordability. ${ }^{1}$ However, treatment planning in the rehabilitation of a completely edentulous arch using implantsupported prosthesis has been quite challenging. The crowns restored over the implants need to be mechanically strong and esthetically satisfactory. Critical parameters such as stability and distribution of stress on the bone along with clinical health of gingiva play a pivotal role for long-term implant survival. Different types of materials have been used in the past as prosthetic considerations for rehabilitation on implants.

Off late, the most commonly used materials for full-mouth rehabilitation are metal-ceramic and zirconia along with other advanced biomaterials. The metal in the metal-ceramic crown offers strength, while the ceramic layer enhances aesthetics. ${ }^{2,3}$ Despite many clinical trials that have shown positive results, there are contrary studies and possibilities that have demonstrated significant mechanical failures. ${ }^{4,5}$ Hence, there is a need for the development of metal-free prosthesis, which is esthetically satisfying and biocompatible., Eventually, the development of
${ }^{1}$ Department of Dental and Oral Surgery, ASRAM Medical College, Hospital and Research Centre, Eluru, West Godavari, Andhra Pradesh, India ${ }^{2}$ Department of Periodontology, Meenakshi Academy of Higher Education and Research, Faculty of Dentistry, Meenakshi Ammal Dental College and Hospital, Chennai, Tamil Nadu, India

${ }^{3}$ Department of Operations and Information Technology, IBS Hyderabad, ICFAI Foundation for Higher Education (A Deemed to be University), Hyderabad, Telangana, India

${ }^{4}$ Department of Periodontology, Maktoum Bin Hamdan Dental University College, Dubai, UAE

${ }^{5}$ Department of Prosthodontics and Implantology, Meenakshi Academy of Higher Education and Research, Faculty of Dentistry, Meenakshi Ammal Dental College and Hospital, Chennai, Tamil Nadu, India

${ }^{6}$ Department of Periodontics, Guntur, Andhra Pradesh, India

Corresponding Author: Jaideep Mahendra, Department of Periodontology, Meenakshi Academy of Higher Education and Research, Faculty of Dentistry, Meenakshi Ammal Dental College and Hospital, Chennai, Tamil Nadu, India, Phone: +91 9444963973, e-mail: jaideep_perio@madch.edu.in

How to cite this article: Yemineni BC, Mahendra J, Jigeesh $\mathrm{N}$, et al. Comparison of Stress Distribution and Deformation of Four Prosthetic Materials in Full-mouth Rehabilitation with Implants: A Three-dimensional Finite Element Study. J Contemp Dent Pract 2020;21(11):1210-1217.

Source of support: Nil

Conflict of interest: None

(c) Jaypee Brothers Medical Publishers. 2020 Open Access This article is distributed under the terms of the Creative Commons Attribution 4.0 International License (https://creativecommons.org/licenses/by-nc/4.0/), which permits unrestricted use, distribution, and non-commercial reproduction in any medium, provided you give appropriate credit to the original author(s) and the source, provide a link to the Creative Commons license, and indicate if changes were made. The Creative Commons Public Domain Dedication waiver (http://creativecommons.org/publicdomain/zero/1.0/) applies to the data made available in this article, unless otherwise stated. 
zirconium oxide $\left(\mathrm{ZnO}_{2}\right)$ as the base material for prosthesis has led to the progression in the dental ceramic industry. ${ }^{8,9}$ It was observed to have high mechanical strength and less prone to low-temperature degradation along with unique transformation toughening properties. ${ }^{10,11}$

Reinforced polymers have a significant advantage over dental ceramics through their reduced impact force on implants. The base material is polyether ether ketone (PEEK), which was developed as a veneer-compatible framework material. ${ }^{12}$ Trinia polymeric material, due to its anisotropy and balanced blending of components, is a biopolymer that can be used successfully in the rehabilitation of the affected functions of the orofacial system. According to Aldafeeri et al., the modulus of elasticity of Trinia is comparable to human dentin. ${ }^{13}$

Finite element analysis is the de facto technology for detailed stress analysis and deformation prediction. It is a very versatile and powerful tool in making any biomaterial design portfolio. As deformation and von Mises stress distribution play a pivotal role in implant survival, various studies were performed in the recent past to identify a better prosthetic material that can downregulate deformation and stress distribution on implant assembly in fullmouth rehabilitation with implants. ${ }^{14}$ Most studies have failed to demonstrate a specific prosthetic material that can fulfill the same. The shortcomings of the previous studies initiated the present hypothesis on comparing the stress distribution and deformation of the alveolar bone, implant, abutment, and abutment screw using metal-ceramic, zirconia, PEEK, and Trinia as prosthetic materials for full-mouth cementretained implant prosthesis using finite element analysis, thus serving as a better material of choice for an implant-supported prosthesis.

The mechanical properties form the basis of the characterization of any prosthesis. Overall, the primary purpose of our study was to identify and compare significant deformation, excessive stress exerted by various prosthetic materials on the implant assembly, abutment, and abutment screw.

\section{Materials and Methods}

The study was conducted in the Department of Dental and Oral Surgery, ASRAM Medical College, Hospital and Research Center, Eluru. Clinical models were obtained from a patient rehabilitated with full-mouth implant-supported prosthesis. Eventually, the clinical models were scanned, and the occlusal pattern was replicated on the finite element model.

\section{Implant Designing}

Four bone models were designed from the tomographic scans of a completely edentulous patient. Six conical titanium implants of dimensions, $4.5 \times 11.5 \mathrm{~mm}$, connected to a screw-retained internal hexagonal abutment, were designed (Fig. 1). ${ }^{15}$ The implant positions were marked by scanning the models obtained from clinical impressions, as they provide more clinically relevant models (Fig. 2A). The physical properties of the implant components, bone, and crowns were used for meshing the three-dimensional finite element models (Fig. 2B). Implants were positioned bilaterally in the canine region, which were considered as anterior, along with implants in the second premolar and second molar regions considered posterior (Fig. 2C).

\section{Prosthetic Materials}

Each of the four models were loaded separately with four different prosthetic materials, namely, metal-ceramic, zirconia, PEEK, and

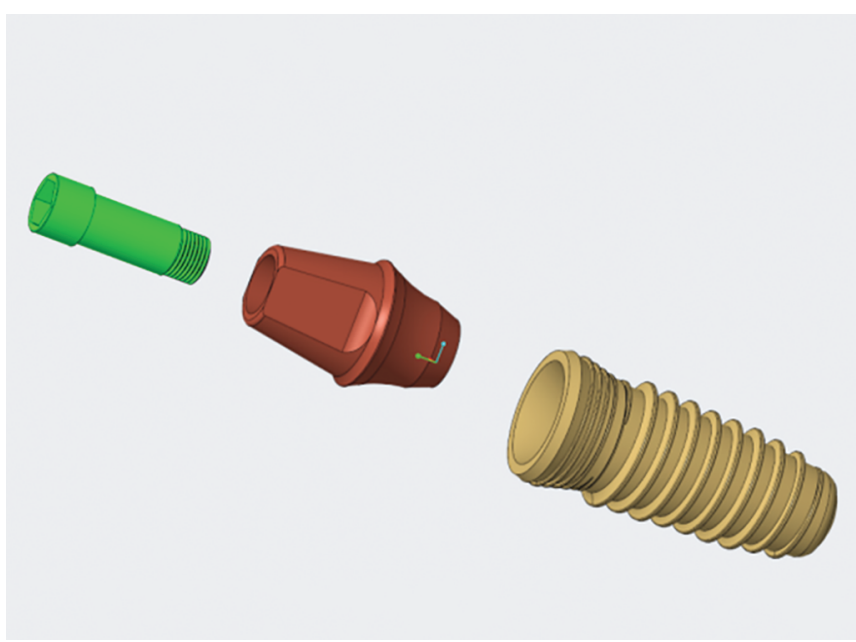

Fig. 1: Conical implant of $4.5 \times 11.5 \mathrm{~mm}$, with a screw-retained internal hexagonal abutment designed using Solidworks software

Trinia, which were considered for comparison with regard to deformation and von Mises stress. Metal-ceramic crowns were designed with silver palladium alloy over which $0.5 \mathrm{~mm}$ of porcelain was layered. Other prosthetic materials were monolithic type and were designed based on the properties of Zirconia, PEEK, and Trinia.

\section{Elements and Nodes}

After designing the models consisting of bone, implant assembly, and prosthesis, the solid geometries were exported for finite element analysis. ANSYS software (ANSYS 16.0, ANSYS Inc., Houston, TX, USA) in.STEP format was used for the study. Following this, the tetrahedral elements formed the mesh. A convergence test of $10 \%$ determined the total number of control elements of the mesh for 370.345 (Table 1).

\section{Finite Element Analysis}

A load of $50 \mathrm{~N}$ was applied to the area of occlusal points, which were marked based on the scanned models. The occlusal loading points were confirmed using opposing occlusion from these models.

The deformation and von Mises stress distribution were evaluated and compared for implant assembly, abutment, and abutment screw under simulated occlusal forces using the finite element analysis method. This method has a wide application in the study of dental implants. ${ }^{16,17}$

\section{Results}

The primary outcome variable of our study is the stress distribution on implant assembly, abutment, and abutment screw. The secondary outcome variable is the calculation amount of deformation on implant assembly and abutment screw. To facilitate the interpretation of the data, we separated the results comparing the deformation and stress in the implant assembly for each of the prosthetic material used.

\section{Stress Distribution}

Stress distribution was presented using von Mises qualitative data. von Mises Stress on Implants

The stress exerted on implants was higher for zirconia prosthesis: 458.8 MPa (Fig. 3B), followed by metal-ceramic: 191.6 MPa (Fig. 3A), 
PEEK: 191.39 MPa (Fig. 3C), and Trinia: 155.92 MPa (Fig. 3D). In all four groups of prosthetic materials, commonly, higher stresses were exerted on the anterior implants than the posterior, with supreme being on the canine region implant. Regarding the stress within the implants, it was observed that maximum stress was exerted on the apical region of implants (Fig. 4).

\section{von Mises Stress on Abutment}

The stress exerted on implant abutments was higher in the case of zirconia prosthesis (126.07 MPa) (Fig. 7C), followed by PEEK (54.612 MPa), metal-ceramic (54.499 MPa) (Fig. 5C), and Trinia (12.686 MPa) (Fig. 6). von Mises stress values on abutments showed higher stresses exerted on the anterior implants than the posterior for all four groups of prosthetic materials. On individual implant abutments, maximum forces were seen on the abutment in relation to the canine region implant for zirconia prosthesis (Fig. 7). Trinia prosthesis has shown the least stress exerted on the abutments when compared to the other three groups.
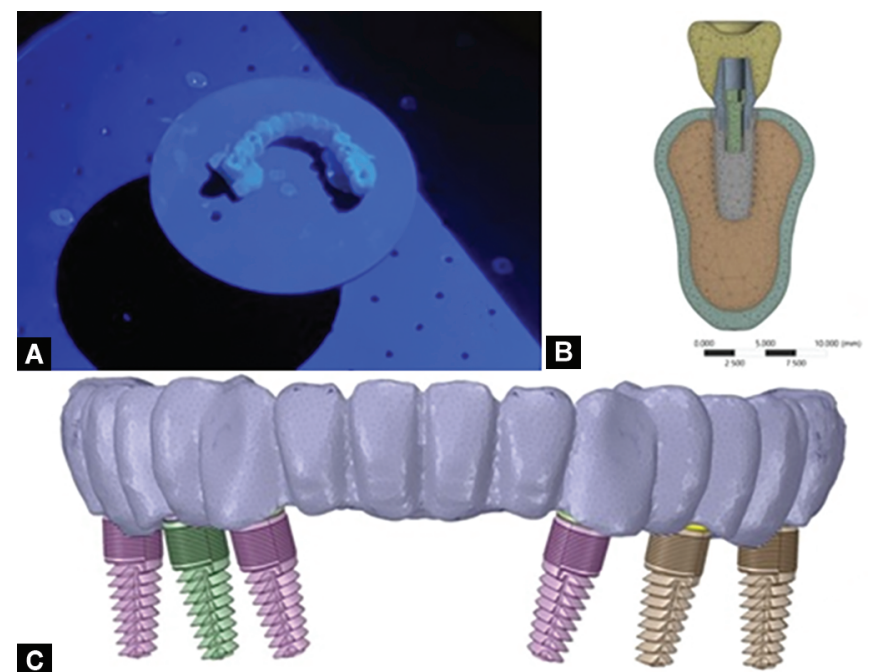

Figs 2A to C: (A) Scanning clinic prosthesis model for occlusal form; (B) Meshed 3-dimensional model; (C) Model simulating position of implants and crowns

\section{von Mises Stress on Abutment Screw}

The stress exerted on implant abutment screw was higher for zirconia prosthesis (37.344 MPa) (Fig. 7), followed by PEEK (15.98 $\mathrm{MPa}$ ), metal-ceramic (15.946 MPa) (Fig. 5D), and Trinia (2.8582 MPa)

(Fig. 8). von Mises stress on the abutments screw was observed to

Table 1: Specifications and composition of the meshed models

\begin{tabular}{ll}
\hline Number of elements in the mesh & 60,193 \\
Number of elements in implants & 10,253 \\
Number of elements in the mandible & 86,888 \\
Number of nodes in the model & $1,053,272$ \\
Number of Nodes within the implant & 18,461 \\
Number of nodes in the mandible & 147,815 \\
Active connections/contact points in & 95
\end{tabular}

model
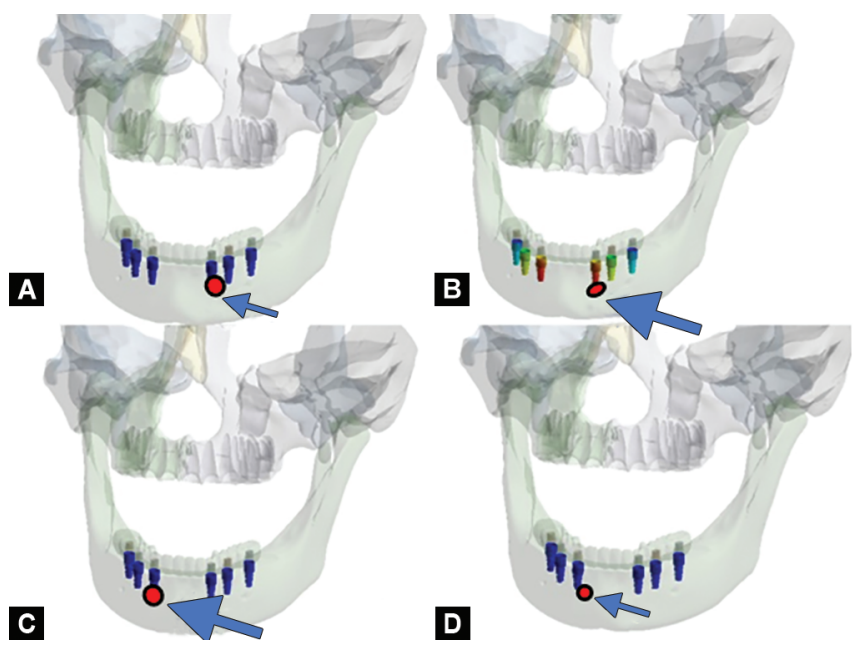

Figs 3A to D: von Mises stress on individual implants for four prostheses. Note the area marked as red where the highest stress was recorded (A) Metal-ceramic; (B) Zirconia; (C) PEEK; (D) Trinia

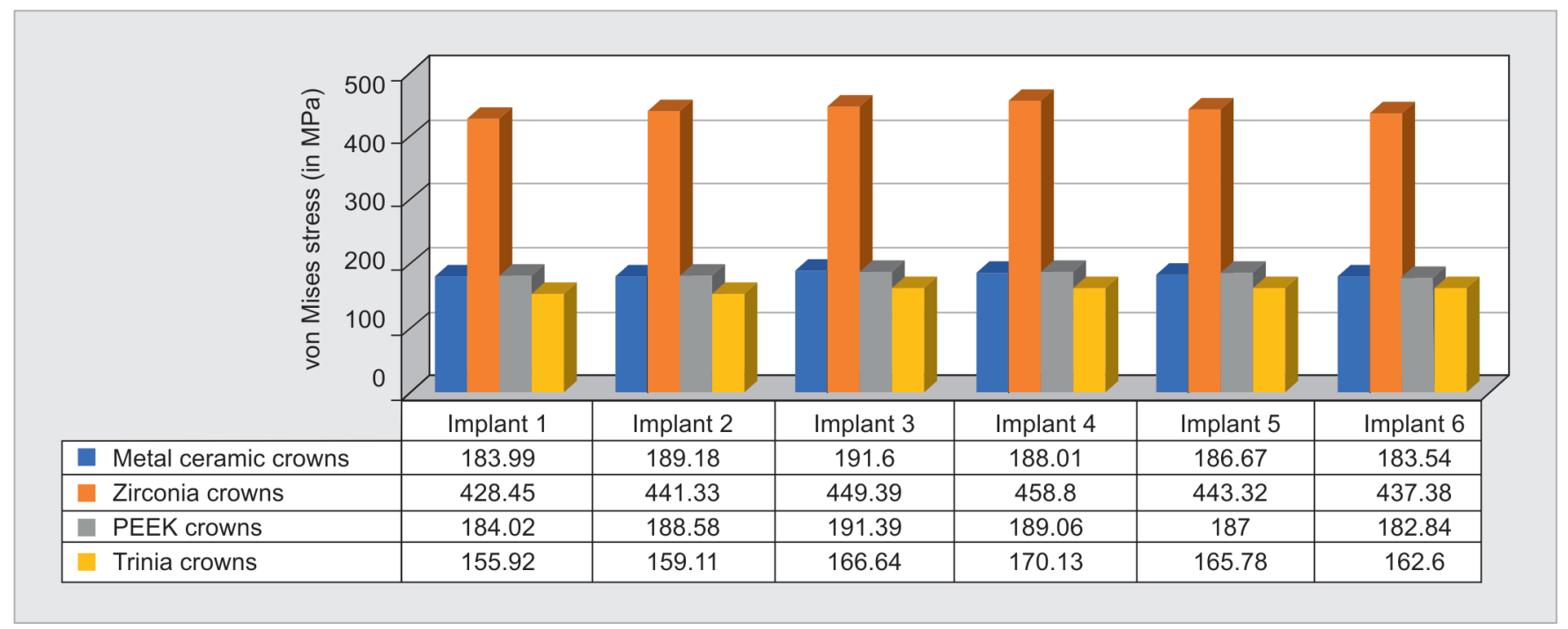

Fig. 4: von Mises stress on implants 
be higher on the implant in posterior than that of anterior implants for all prosthetic materials.

\section{Total Deformation}

\section{Deformation of Implant Assembly}

The maximum deformation of the implant assembly was seen with respect to zirconia prosthesis (Fig. 7), which was $0.20231 \mathrm{~mm}$, followed by Trinia $(0.0964 \mathrm{~mm})$, metal-ceramic (Fig. 5B) $(0.0892 \mathrm{~mm})$, and PEEK (0.0890 $\mathrm{mm})$ prosthesis (Fig. 9).

\section{Deformation of Implant Abutment}

The maximum deformation of the implant assembly was seen for zirconia prosthesis, which was $0.19741 \mathrm{~mm}$, followed by Trinia $(0.094$ $\mathrm{mm})$, metal-ceramic $(0.0871 \mathrm{~mm})$, and PEEK $(0.0870 \mathrm{~mm})$ prosthesis (Fig. 10). Abutments in canine region implants showed higher deformation in comparison to that of other implants.
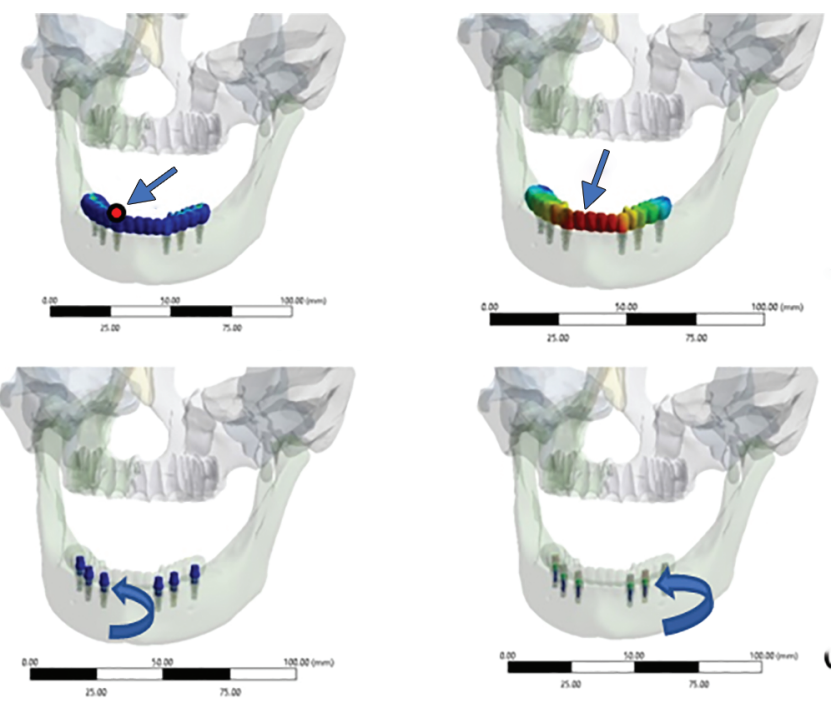

Figs 5A to D: Metal-ceramic prosthesis. The area marked as red indicates highest stress recorded. The region pointed with arrow indicates area with highest deformation recorded; (A) von Mises stress on prosthesis; (B) Deformation observed on prosthesis; (C) von Mises stress on abutments; (D) von Mises stress on abutment screw

\section{Deformation of Implant Abutment Screw}

The maximum deformation on the abutment screw was observed in zirconia prosthesis on canine region implant $(0.1989 \mathrm{~mm})$, followed by Trinia prosthesis $(0.09479 \mathrm{~mm})$, metal-ceramic $(0.08779 \mathrm{~mm})$, and PEEK $(0.08777 \mathrm{~mm}$ ) (Fig. 11). A higher amount of deformation was observed in the abutment screws of anterior implants with respect to all the groups of prostheses.

\section{Discussion}

For implant-supported fixed prosthesis, the stresses that occur as a result of functional forces are transferred to the supporting bone by restorative material and implant assembly. Extreme stress concentration at the point of contact must be eliminated, failing which, there can be implant failures at the level of an abutment, abutment screw, or the implant itself. Hence, stress transferred to the abutment and abutment screw through various types of prosthetic materials becomes an essential factor to be analyzed. Prosthetic materials such as zirconia and metal-ceramic are known for their high mechanical strength and fracture toughness. However, these materials have shown a lack of proper evidence in minimizing the stress distribution on the implant assembly and underlying bone. Finite element analysis could be the gold standard in analyzing stress distribution and deformation parameters in such cases. Finite element analysis is considered to be an appropriate method for internal stress investigation and hence was used in the present study to test and compare the affinity of materials. The behavior of the whole model is usually described by an enormously large set of equations that describe the behavior of individual elements joined together. Often, to obtain reliable results, the number of elements and nodes must be 30,000 to 200,000 , where increasing the number of elements provides more accurate results. Nevertheless, the increase in the number of nodes and elements prolongs the time needed for the analysis. ${ }^{18}$ Hence, in most of the studies, the number of elements and nodes have either been limited or been reduced outside the area of interest. The model used in the present study had an area of interest that was separated into many small, simple blocks or elements after which the structure was entirely made by joining together the sets of elements. It had an average of 60,193 elements and 1,053,272 nodes. These numbers

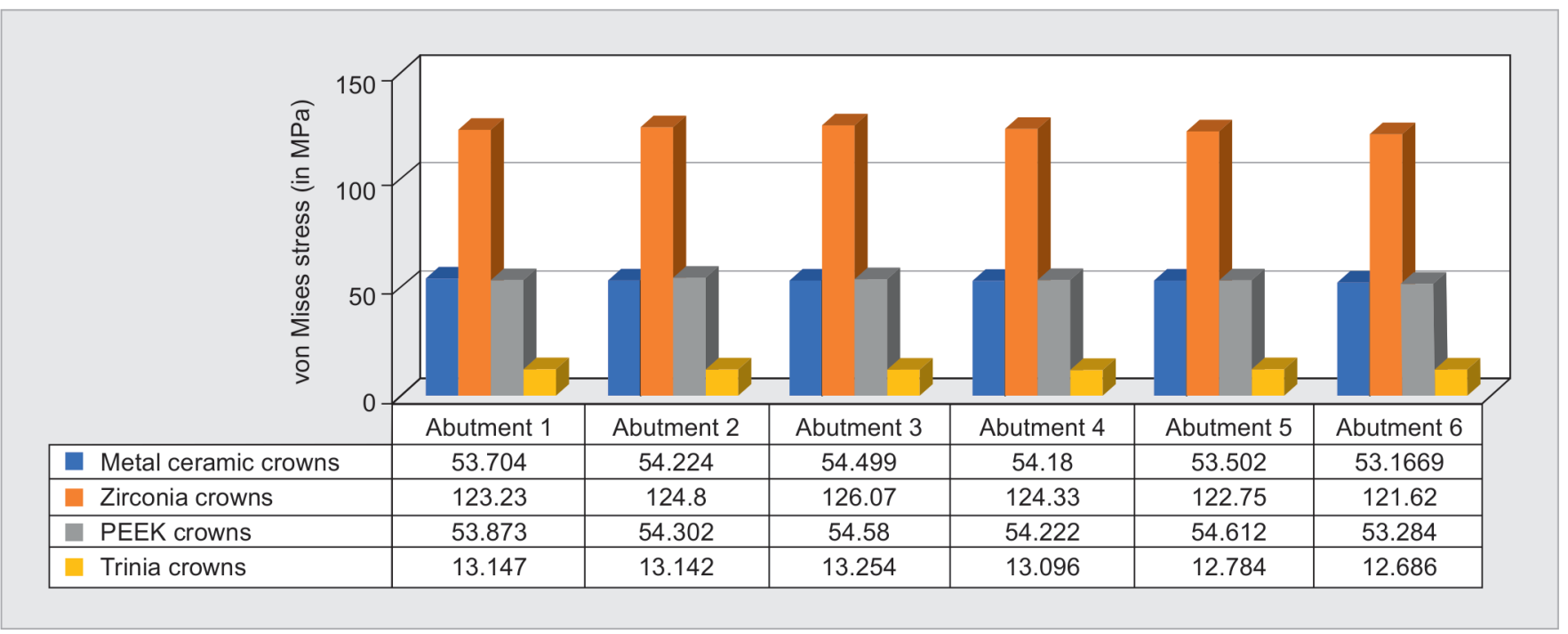

Fig. 6: von Mises stress on abutment 
were well above the number of elements and nodes used in the vast majority of studies using the finite element analysis method. This helped us to analyze the stress accurately within implant and implant components along with the surrounding bone.

Understanding the principles, applications, and limitations of the finite element analysis method is vital for the clinician to interpret the findings of such observations and apply the conclusions to the clinical scenario for better results. Limited studies in the past have reported the impact of various prosthetic materials on the stress distribution and deformation pattern of implants and bone using experimental methods such as in vivo strain-gauge measurements, ${ }^{18}$ histologic studies, ${ }^{19,20}$ and in vitro experiments ${ }^{21}$ in addition to finite element analysis. Also, there is confined evidence on various biomaterials and their resultant stress distribution and deformation on implant assembly and underlying osseous
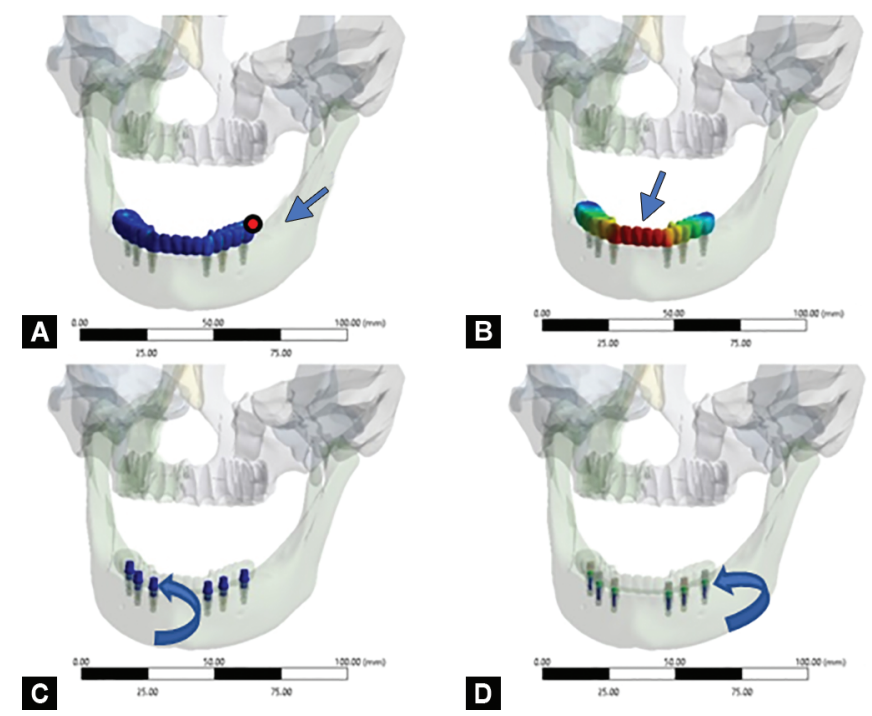

Figs 7A to D: Zirconia prosthesis. The area marked as red indicates highest stress recorded. The region pointed with arrow indicates area with highest deformation recorded; (A) von Mises stress on prosthesis; (B) Deformation observed on prosthesis; (C) von Mises stress on abutments; (D) von Mises stress on abutment screw tissues in full-mouth rehabilitation using a finite element analysis method. ${ }^{22,23}$ To the best of our knowledge, this is the first study to compare von Mises stress distribution and total deformation of prosthetic materials (metal ceramic, zirconia, PEEK, and Trinia) on the implant prosthesis and surrounding bone.

In this study, the use of different prosthetic materials significantly affected stress transmission to bone and implant components. Ironically, materials with high strength recorded higher stress. Differences in the von Mises stress pattern between metal-ceramic and PEEK were observed. However, still, no significant difference is seen, which could be due to the fact that they have nearly similar elastic moduli. On the other hand, zirconia with its high strength and elastic modulus exhibited highest stress distribution, whereas Trinia crowns showed least stress distribution.

The review of literature over the past 20 years has observed the existence of force transmitting capacity of resilient dental materials. Skalak ${ }^{24}$ stated that implant when loaded with rigid occlusal materials with high, Young's modulus, resulted in a higher impact on the underlying bone. He concluded that resin as an occlusal material acts as a shock absorbent and in turn resulted in less stress distribution on implants; however, it cannot be widely used to stabilize the occlusal relationship and hence cannot be considered as an occlusal material of choice; this, concept enlightened that rigid materials induce high impulse load on implants and skeletal tissues. In an in vitro study done by Gracis et al., ${ }^{25}$ it was concluded that the harder and stiffer the occlusal material, the higher would be the force transmitted onto the implant. Menini et al. ${ }^{26}$ analyzed the shock-absorbing capacity of restorative materials and concluded that the type of prosthetic material used significantly affect implant stress distribution and load transfer. Our results were in accordance with the studies mentioned earlier, which showed that zirconia, which is a highly rigid material, exhibited higher forces on the implant, abutment, and abutment screw and surrounding bone when compared to materials with a lower modulus of elasticity such as Trinia and PEEK. While comparing the stress distribution of metalceramic with the other materials, it was considered as optimal. The results were superior to that of zirconia. This was in accordance with Sertgöz et al. ${ }^{16}$ who investigated the effect of superstructure material on stress distribution in an implant-supported fixed

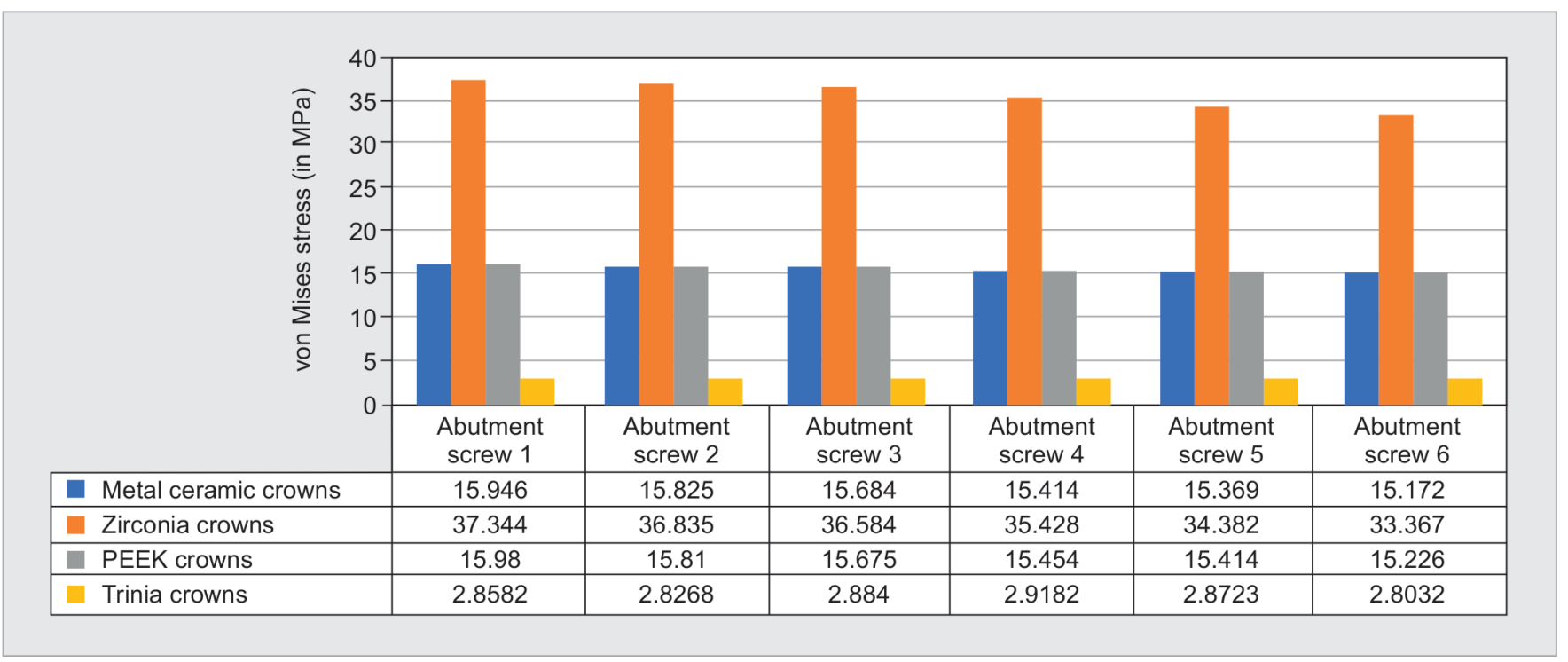

Fig. 8: von Mises stress on abutment screw 


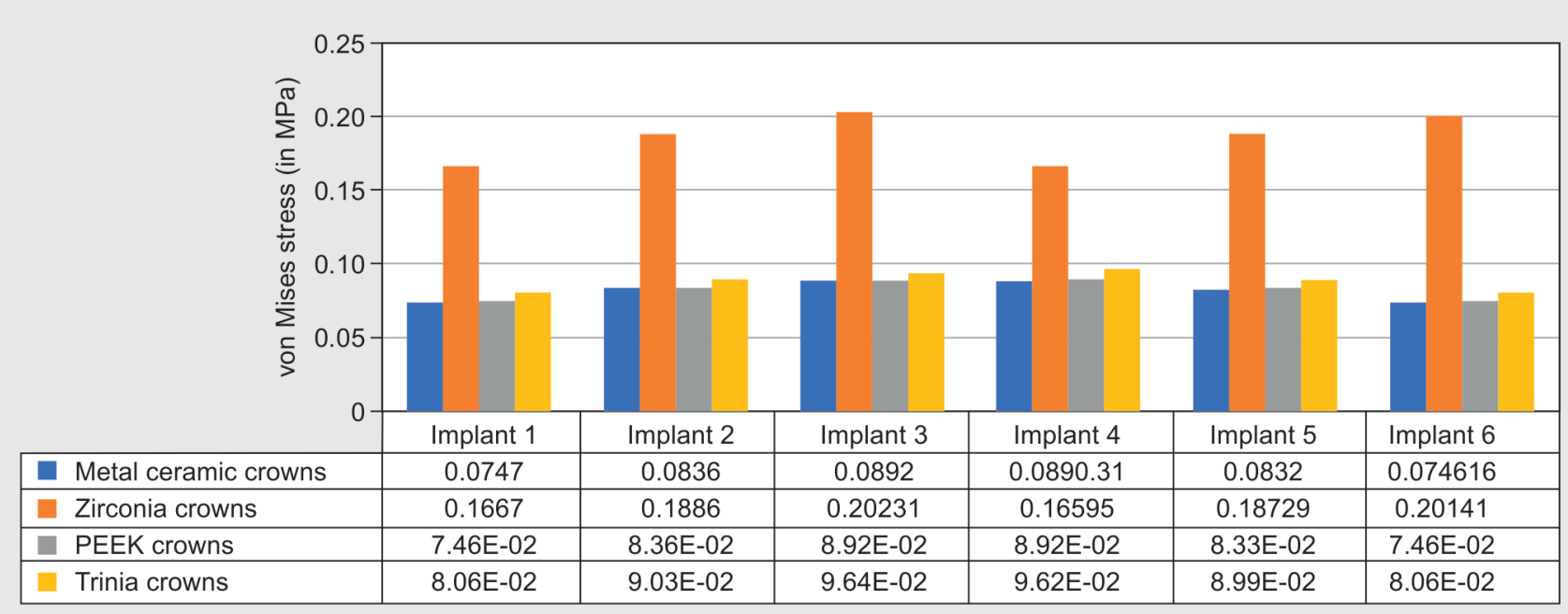

Fig. 9: Deformation of implant assembly

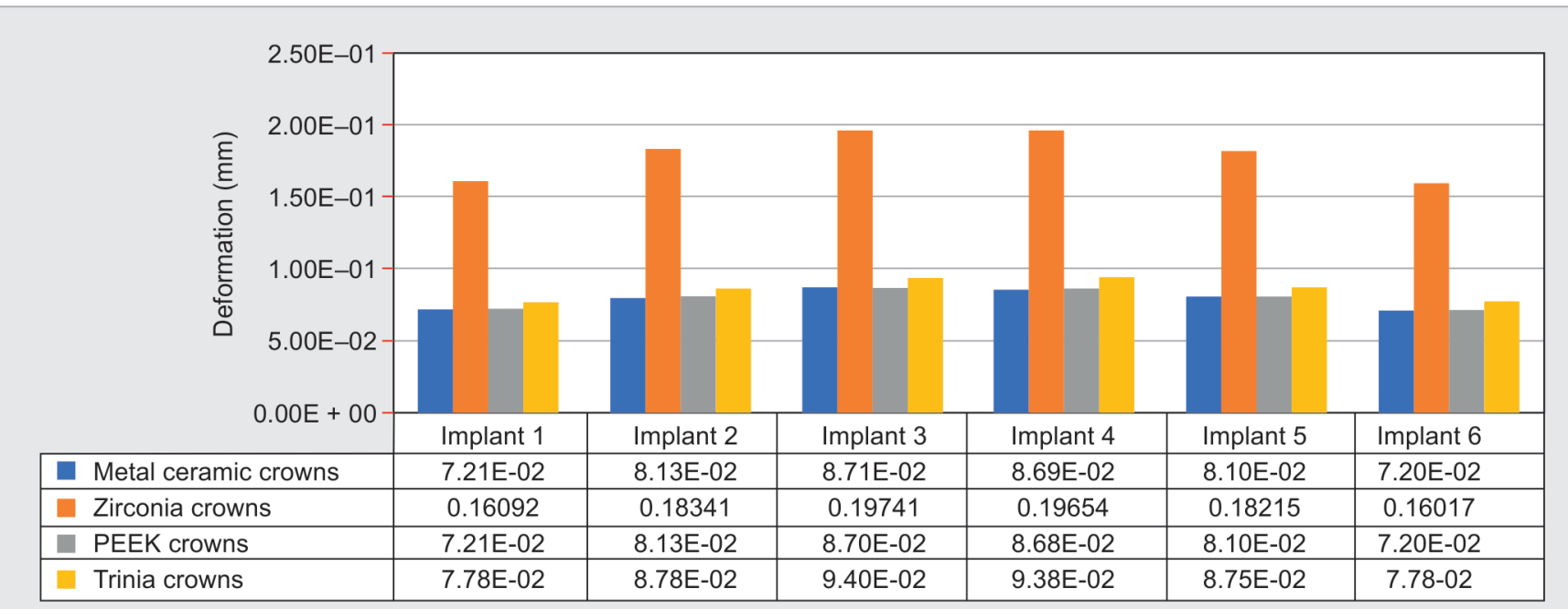

Fig. 10: Deformation of abutment

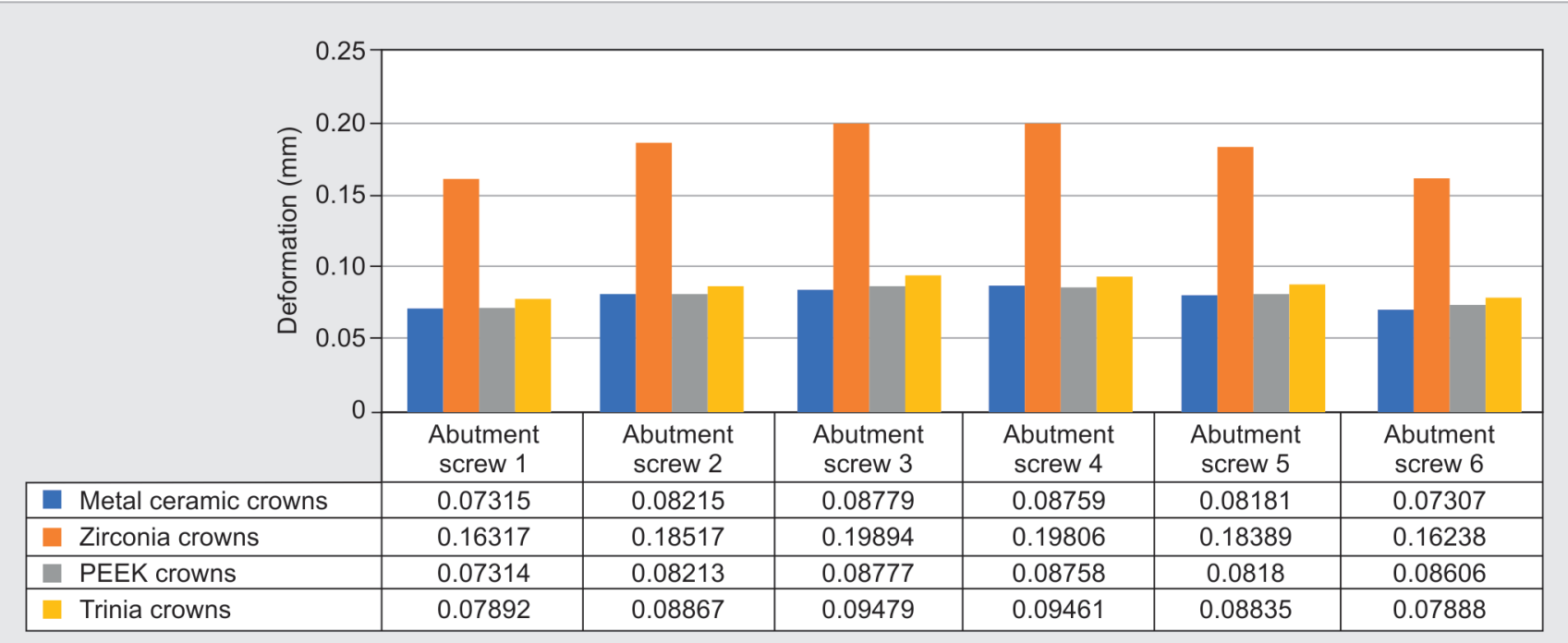

Fig. 11: Deformation of abutment screw 
prosthesis, and the optimal materials were cobalt-chromium for the framework and porcelain for the occlusal surface.

In the present study, Von Mises stress distribution on individual implant components (implant, abutment, and abutment screw) was observed. The stress concentration on the individual implants was high at the apical region of the implants, which contradicts the results demonstrated by Papavasiliou et al. ${ }^{17}$ who stated higher stresses at the crestal level of implants than apical areas. In our study, higher stress was recorded at the neck of the abutment. In the case of abutment screw, higher stresses were recorded at the neck and upper portion of the thread of the screw. These findings suggest that abutment screw at the level of collar and thread can be the most common site of fracture. ${ }^{26-28}$

Hoshaw et al. ${ }^{19}$ stated that von Mises stress estimation is also the scale for estimating the initiation of deformation in biomaterials. The maximum deformation and von Mises stress were concentrated in the anterior part of the mandible, which showed that the anterior implants took the maximum amount of stress compared to the posterior implants. This finding could be attributed to the fact that the anterior part of the mandible is resilient. In the present study, while using a single span bridge, the force was eventually transferred to the prosthesis (Figs 7 and 5A) and implant assembly. Similarly, Çaglar et al. ${ }^{29}$ also suggested that anterior teeth took a higher load in case of a complete rehabilitation single-span bridge. Our results were contradictory to the results of studies conducted by Hazari et al., ${ }^{30}$ where the maximum stress point was localized to the zone between the canine and the first premolar.

In a natural tooth, elastic deformation of the periodontal ligament aid in the micromovement leading to minimal stress being transferred to the underlying bone. On the other hand, as implants lack the periodontal ligament, these micromovements are transferred directly onto the peri-implant bone. Micromovements greater than $150 \mu \mathrm{m}$ can potentially lead to loss of implant osseointegration. ${ }^{31}$

In the present study, the maximum deformation of the implant assembly was seen to be significantly high with respect to zirconia prosthesis than that of metal-ceramic, PEEK, and Trinia. The deformation was high on implants placed in canine region, than the implants placed posteriorly for all prosthetic groups in the study. The amount of deformation exhibited by the abutment screws while using zirconia as prosthetic material was much higher than the other materials. These higher deformation values of the abutment screws could lead to screw loosening of the implant-abutment complex, which could be the initiation of failure of the prosthesis. The micro deformation of an implant can potentially damage the bone-implant interface causing possible loss of osseointegration, further leading to bone loss.

Tartuk et al. ${ }^{32}$ compared the load-bearing capacities of monolithic PEEK, zirconia, and ceramic molar crowns using the final failure force and fracture load. They concluded with no significant difference between the PEEK and ceramic. Similarly, Saraswathi et al. ${ }^{33}$ and Tribst et al. ${ }^{34}$ also found no statistical difference in the load-bearing capacities of zirconia (monolithic and layered) compared with metal-ceramic crowns, titanium, and polyurethane, respectively. This is contrary to the results of our study, where the substantial difference was observed on the stress exerted by PEEK and ceramic based prosthetic materials.

In the context of the present study, although metal-ceramic and zirconia are prosthetic biomaterials of choice in modernday dentistry, one must consider the specific vital mechanical properties of the prosthesis that ultimately dictate its functional efficiency and longevity. The stress distribution and deformation of these biomaterials might play a crucial role in decision-making for prosthetic material as a choice in full-mouth rehabilitation with an implant-supported prosthesis.

Finite element study models would need the bone to implant contact to be $100 \%$ as used in the present study, where the general range of contact falls in the range of $30-70 \%$. The present study simulates a close clinical situation, but not exact; hence, the interpretation of the results needs more wariness for application in a clinical scenario.

\section{ConCLUSION}

Higher stresses were exerted on the anterior implants compared to posterior implants in all groups of prosthetic materials in the study. Metal-ceramic and Trinia exhibited less stress distribution. Metal-ceramic and PEEK showed less deformation. Keeping in mind that Trinia and PEEK being latest advancements as prosthetic biomaterials, and encouraging positive results shown by them in our study, they could emerge as new implant prosthetic materials for future in vitro and in vivo research and clinical application in the field of implantology.

\section{References}

1. Papaspyridakos $P$, Chen C-J, Singh $M$, et al. Success criteria in implant dentistry: a systematic review. J Dent Res 2012;91(3):242-248. DOI: 10.1177/0022034511431252.

2. Robati Anaraki M, Torab A, Mounesi Rad T. Comparison of stress in implant-supported monolithic zirconia fixed partial dentures between canine guidance and group function occlusal patterns: a finite element analysis. J Dent Res Dent Clin Dent Prospects 2019;13(2):90-97. DOI: 10.15171/joddd.2019.014.

3. Walton TR. A 10-year longitudinal study of fixed prosthodontics: clinical characteristics and outcome of single-unit metal-ceramic crowns. Int J Prosthodont 1999;12(6):519-526.

4. Quirynen M, Naert I, van Steenberghe D. Fixture design and overload influence marginal bone loss and fixture success in the Brånemark system. Clin Oral Implants Res 1992;3(3):104-111. DOI: 10.1034/j.16000501.1992.030302.x.

5. Baggi L, Pastore S, Di Girolamo M, et al. Implant-bone load transfer mechanisms in complete-arch prostheses supported by four implants: A three-dimensional finite element approach. J Prosthet Dent 2013;109(1):9-21. DOI: 10.1016/S0022-3913(13)60004-9.

6. Bankoğlu Güngör M, Aydın C, Yılmaz H, et al. An overview of zirconia dental implants: basic properties and clinical application of three cases. J Oral Implantol 2014;40(4):485-494. DOI: 10.1563/AAIDJOI-D-12-00109.

7. Tettamanti S, Millen C, Gavric J, et al. Esthetic evaluation of implant crowns and peri-implant soft tissue in the anterior maxilla: comparison and reproducibility of three different indices: Comparison and reproducibility of three esthetic indices for implant crowns. Clin Implant Dent Relat Res 2016;18(3):517-526. DOI: 10.1111/ cid.12306.

8. Guazzato M, Albakry M, Ringer SP, et al. Fracture toughness and microstructure of a selection of all-ceramic materials. Part II. Zirconiabased dental ceramics. Dent Mater Off Publ Acad Dent Mater 2004;20(5):449-456. DOI: 10.1016/j.dental.2003.05.002.

9. Grech J, Antunes E. Zirconia in dental prosthetics: a literature review. J Mater Res Technol 2019;8(5):4956-4964. DOI: 10.1016/j. jmrt.2019.06.043.

10. Bona A, Pecho O, Alessandretti R. Zirconia as a dental biomaterial. Materials 2015;8(8):4978-4991. DOI: 10.3390/ma8084978.

11. Badran N, Abdel Kader S, Alabbassy F. Effect of incisal porcelain veneering thickness on the fracture resistance of CAD/CAM 
zirconia all-ceramic anterior crowns. Int J Dent 2019;2019:1-12. DOI: $10.1155 / 2019 / 6548519$.

12. Emera K, Altonbary R, Elbashir G, et al. Comparison between all zirconia, all PEEK, and zirconia-PEEK telescopic attachments for two implants retained mandibular complete overdentures: in vitro stress analysis study. J Dent Implants 2019;9(1):24.DOI: 10.4103/jdi.jdi_6_19.

13. Aldafeeri HR, Ghazy MH. Marginal accuracy of machinable monolithic zirconia laminate veneers. 2019;18:67-74. DOI: 10.9790/08531805176774.

14. Watanabe F, Uno I, Hata $Y$, et al. Analysis of stress distribution in a screw-retained implant prosthesis. Int J Oral Maxillofac Implants 2000;15(2):209-218.

15. Ciftçi $Y$, Canay $S$. The effect of veneering materials on stress distribution in implant-supported fixed prosthetic restorations. Int J Oral Maxillofac Implants 2000;15(4):571-582.

16. SertgözA. Finite element analysis study of the effect of superstructure material on stress distribution in an implant-supported fixed prosthesis. Int J Prosthodont 1997;10(1):19-27.

17. Papavasiliou G, Kamposiora P, Bayne SC, et al. Three-dimensional finite element analysis of stress-distribution around single tooth implants as a function of bony support, prosthesis type, and loading during function. J Prosthet Dent 1996;76(6):633-640. DOI: 10.1016/ S0022-3913(96)90442-4.

18. Benzing UR, Gall H, Weber H. Biomechanical aspects of two different implant-prosthetic concepts for edentulous maxillae. Int J Oral Maxillofac Implants 1995 Apr;10(2):188-198.

19. Hoshaw SJ, Brunski JB, Cochran GVB. Mechanical loading of Brånemark implants affects interfacial bone modeling and remodeling. Int Oral Maxillofac Implants 9(3):345-360.

20. Vaillancourt H, Pilliar RM, McCammond D. Finite element analysis of crestal bone loss around porous-coated dental implants. J Appl Biomater Off J Soc Biomater 1995;6(4):267-282. DOI: 10.1002/ jab.770060408.

21. Simon BR, Woo SLY, Stanley GM, et al. Evaluation of one-, two-, and three-dimensional finite element and experimental models of internal fixation plates. J Biomech 1977;10(2):79-86. DOI: 10.1016/0021-9290(77)90071-9.

22. van Zyl PP, Grundling NL, Jooste $\mathrm{CH}$, et al. Three-dimensional finite element model of a human mandible incorporating six osseointegrated implants for stress analysis of mandibular cantilever prostheses. Int J Oral Maxillofac Implants 1995;10(1):51-57.

23. Misch CM, Ismail YH. Finite element stress analysis of tooth-to-implant fixed partial denture designs. J Prosthodont Off J Am Coll Prosthodont 1993;2(2):83-92. DOI: 10.1111/j.1532-849X.1993.tb00388.x.
24. Skalak R. Biomechanical considerations in osseointegrated prostheses. J Prosthet Dent 1983;49(6):843-848. DOI: 10.1016/00223913(83)90361-X.

25. Gracis SE, Nicholls JI, Chalupnik JD, et al. Shock-absorbing behavior of five restorative materials used on implants. Int J Prosthodont 1991;4(3):282-291.

26. Menini $M$, Conserva $E$, Tealdo $T$, et al. The use of a masticatory robot to analyze the shock absorption capacity of different restorative materials for implant prosthesis. J Biol Res 2011. DOI: 10.4081/ jbr.2011.4636.

27. Aglietta M, Siciliano VI, Zwahlen M, et al. A systematic review of the survival and complication rates of implant supported fixed dental prostheses with cantilever extensions after an observation period of at least 5 years. Clin Oral Implants Res 2009;20(5):441-451. DOI: 10.1111/j.1600-0501.2009.01706.x.

28. Luterbacher S, Fourmousis I, Lang NP, et al. Fractured prosthetic abutments in osseointegrated implants: a technical complication to cope With. Clin Oral Implants Res 2000;11(2):163-170. DOI: 10.1034/j.1600-0501.2000.110209.x.

29. Çaglar A, Bal BT, Karakoca S, et al. Three-dimensional finite element analysis of titanium and yttrium-stabilized zirconium dioxide abutments and implants. Int J Oral Maxillofac Implants 2011;26(5):961-969.

30. Hazari P, Somkuwar S, Yadav N, et al. Different techniques for management of pier abutment: reports of three cases with review of literature. Arch Med Health Sci 2016;4(1):89. DOI: 10.4103/23214848.183343.

31. Szmukler-Moncler $S$, Salama $H$, Reingewirtz $Y$, et al. Timing of loading and effect of micromotion on bone-dental implant interface: review of experimental literature. J Biomed Mater Res 1998;43(2):192-203. DOI: 10.1002/(SICI)1097-4636(199822)43:2<192::AID-JBM14>3.0.CO;2-K.

32. Tartuk BK, Ayna E, Göncü Başaran E. Comparison of the load-bearing capacities of monolithic PEEK. Zirconia and Hybrid Ceramic Molar Crowns Meandros Med Dent J 2019;20(1):45-50. DOI: 10.4274/ meandros.galenos.2018.54269.

33. Saraswathi DD, Leneena G, Madava RB, et al. Comparative evaluation of marginal vertical discrepancies of full zirconia crowns, layered zirconia crowns, and metal ceramic crowns: an in vitro study. J Int Oral Health 2016;8:208-213.

34. Tribst JPM, de Morais DC, Alonso AA, et al. Comparative threedimensional finite element analysis of implant-supported fixed complete arch mandibular prostheses in two materials. J Indian Prosthodont Soc 2017;17(3):255-260. DOI: 10.4103/jips. jips_11_17. 